\title{
PRE-CONSTRUCTION ROCK TREATMENT AND SOIL MODIFICATION PROGRAM USING LOW MOBILITY GROUT TO MITIGATE FUTURE SINKHOLE DEVELOPMENT IN A 2,787.1 SQUARE METER (30,000 SF) MAINTENANCE FACILITY
}

\author{
Steven W. Shifflett \\ Senior Geotechnical Engineer, Louisville District US Army Corps of Engineers, 600 Dr. Martin Luther King Jr. Place \\ Louisville, KY, 40202, USA, Steven.w.shifflett@usace.army.mil
}

\begin{abstract}
The US Army required construction of a 2,787.1 square meters $(30,000 \mathrm{sf})$ maintenance facility supported on shallow foundations at the Fort Campbell Military Installation. During the subsurface investigation a seven foot air-filled void was encountered in the bedrock within the building footprint. Electrical Resistivity Imaging (ERI) was conducted in an attempt to determine the lateral extent of the encountered void and to establish the general prevalence of karst features at the site. Due to uncertainty in the subsurface conditions, a rock treatment and soil modification program was developed which consisted of a series of targeted exploratory grout holes advanced in 126 locations in the structural areas of the building footprint. The intent of the program was not to prevent the development of a soil dropout, but to improve the foundation support of the structure so that the facility would perform acceptably if a future soil dropout were to occur during the design life of the facility. This was achieved by targeting each footing with 3 exploratory grout holes. The intent of each grout injection was 1) to identify the top of rock elevation, 2) determine if a karst feature existed, 3) cap the karst bedrock below the footing and treat defects in the rock, and 4) provide localized improvement of soft soils through the use of low mobility grout columns under each footing. Drilling refusal elevations were obtained for every grout hole and were assumed to represent the top of bedrock. Each exploratory hole was closely monitored for pressure and volume in 0.61 meter (2-foot) stages. Zones where the bedrock had lower elevations or took excessive grout at low pressures were targeted with additional tertiary holes. The tertiary holes were verified with additional SPT sampling. Documented ground improvement was achieved, evident by increased SPT blow counts ranging between 25 to $50+$ post treatment. Based on results from this program, lower grouting pressures could have been utilized as part of the refusal criteria to successfully identify and treat karst features.
\end{abstract}

\section{Geology and Subsurface Exploration}

The project site is located in the Mississippian Plateau, an upland region mostly underlain by Upper Mississippian Series limestone and dolomite assigned to the Ste. Genevieve and St. Louis Members of the Slade Formation. Regional geomorphology includes intense karst development including the Mammoth Cave-Flint Ridge cave system to the northeast. As a result of karst development, the plateau has developed a complex pattern of sinkholes and solution features within the bedrock. A chert zone near the soil/bedrock interface was assumed to mark the contact between the Ste. Genevieve and St. Louis Members. Bedrock at the study site exhibited erratic pinnacles extending into the overburden soils with soil-filled slots extending into the rock unit. During excavation of the site several pinnacles were encountered and removed. Proximal sites to the north, west, and south have a documented history of sinkhole development as shown in Figure 1.

During site reconnaissance, a slight closed surface depression was observed in the building footprint along with three confirmed sinkholes along the southern and western perimeter of the site. Final grades for the site required construction of two retaining walls to level the existing hillside to achieve finished grade. Existing grades in the area of the building footprint required between 0.61 and 3.05 meters ( 2 and 10 feet) of cut to achieve the finish subgrade elevation for the building. Bedrock refusal depths ranged between 5.5 and 12.5 meters (18 and 41 feet) below the ground surface (bgs) based on the geotechnical investigation. Site soils in the northeast and southeast corners of the proposed facility contained 3.1 to 4.6 meters ( 10 to 15 foot) zones of very soft soils with rod drops of 0.3 to 0.61 meters ( 1 to 2 feet) during SPT sampling. The average SPT N-value across the site at a depth of 7.6 meters ( 25 feet $)$ was 7 bpf with several zones recording blow counts of 0 or 1 . Drilling fluid was lost in the two boreholes where rock 


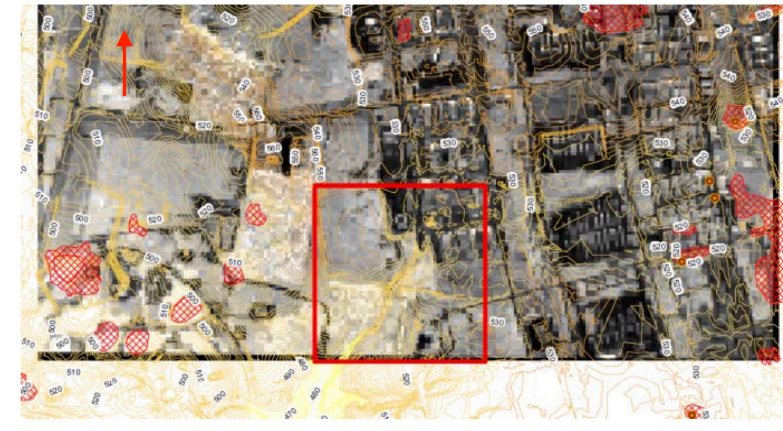

Figure 1. Topography and Locations of Historic Sinkholes and Closed Surface Depressions on Adjacent Sites.

core was obtained and a 2.1 meters ( 7 foot) void was encountered in the bedrock at the NE corner of the building as shown in Figure 2.

Karst features encountered at the site coupled with the existing topography of the area limited options for remediation. Relocation of the facility to a different site or moving the building on the current site were not feasible options. Additional investigations would be required if the design was going to proceed for construction at the current site. Discussions with Geophysicists led to the selection of Electrical Resistivity Imaging (ERI) to attempt to further characterize the subsurface conditions at the site in terms of the varying geology and to attempt to detect any additional karst features using an AGI Super Sting R8 IP system. The geophysical program consisted of 11 traverses totaling 1,219 linear meters (4,000 linear feet) utilizing several arrays including the Dipole-Dipole array, Wenner array, and inverse Schlumberger array. The electrode spacing used for the survey was a function of the geometry of the traverses and ranged from 1.83 meters ( 6 feet) for north-south oriented profiles and 2.44 meters ( 8 feet) for east-west oriented profiles using 56 electrodes. Results were mixed as additional zones of weathered bedrock and pinnacles were identified but the void encountered during drilling was not detected, likely due to interference from a steel fence on site. The test results were consistent with potential karst geology but did not provide conclusive evidence. An exerpt from the ERI Plots is shown in Figure 3. The Geophyscist recommended additional site drilling or Seismic Refraction Techniques. Although the extent of karst issues on the site was still unclear, schedule and funding prevented additional investigations. However, it was clear the risk for future karst development was unacceptably high. If additional investigations would have been initiated the use of Cone Penetrometer Testing (CPT) would likely have

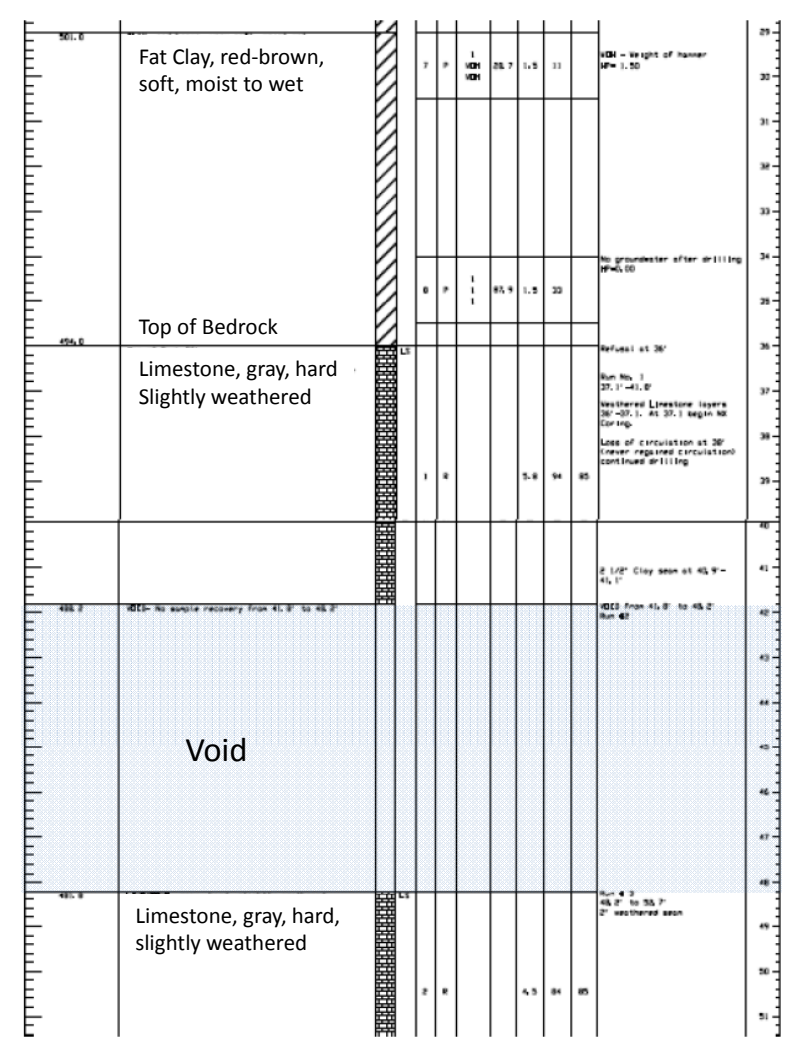

Figure 2. Boring Log of the NE Building Boring from 6.1 to 12.2 meters (20 to 40 feet).

been utilized in an effort to better define the variability in the top of the bedrock surface.

\section{Low Mobility Grouting Rationale}

The subsurface and geophysical investigations led us to believe that the risk to the building would require remediation and also raised awareness that the western portion of the building was also at a very high risk from potential karst features based on interpretation of the ERI results. After meeting with key stakeholders, it was determined that pretreatment of potential karst features in the bedrock would be attempted through low mobility grouting. Traditional low mobility grouting programs using a 2.43 to 3.66 meter ( 8 to 12 foot) grid system under the entire building footprint have been used effectively at Fort Campbell in the past. If such an approach was used at the study site this would have required about 375 holes at a cost of approximately $\$ 1,000,000$. The approach from this case study utilized targeted exploratory grout holes for cap grouting of the bedrock and improvement of the overlying soft soils specifically in the structural areas of the building, and was accomplished with approximately 111 holes (not including tertiary holes) 

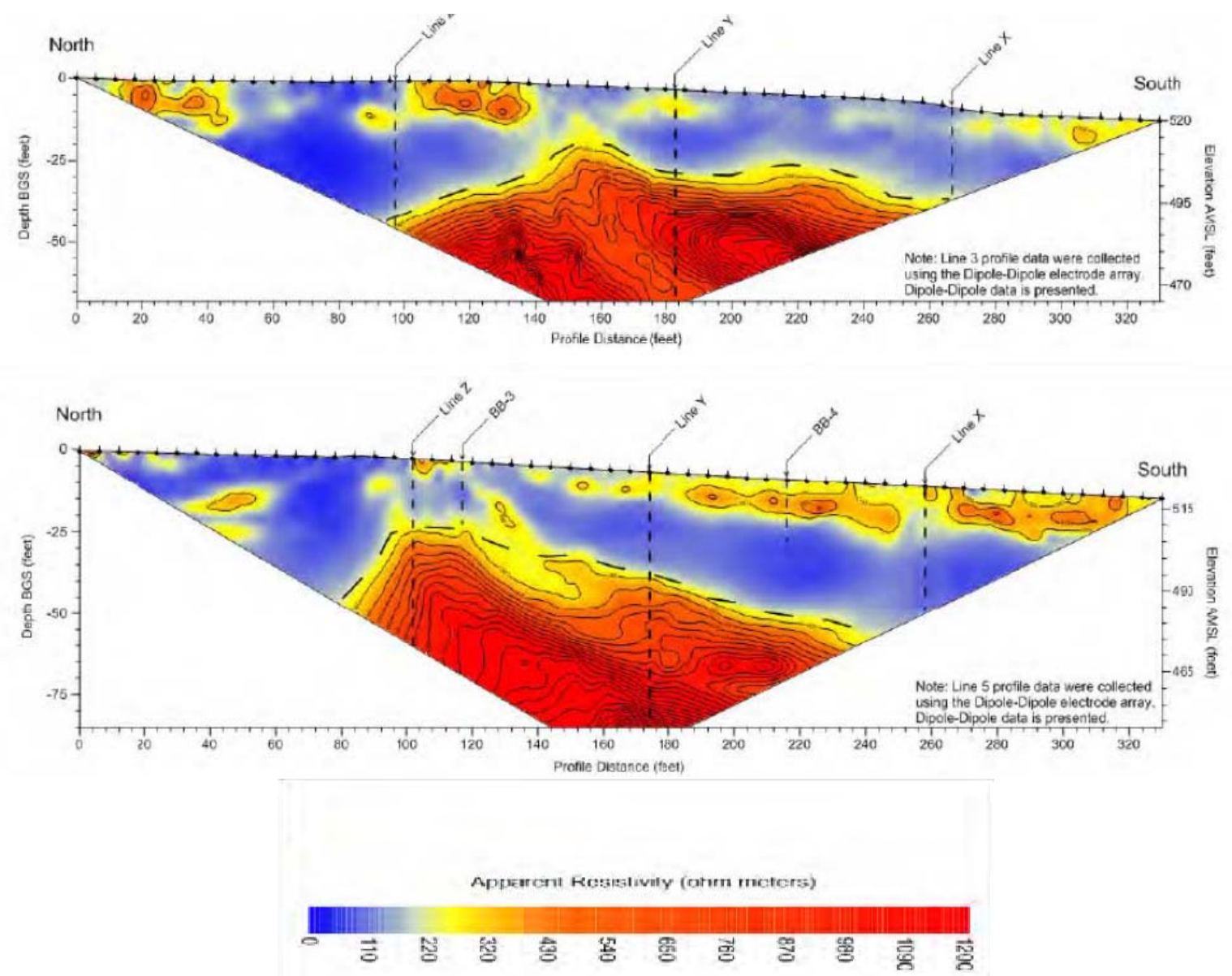

Figure 3. ERI Plots Indicating Pinnacles and Valleys in the Bedrock Surface.

at a cost of approximately $\$ 225,000$. This low mobility grouting methodology consisted of a grout program that required the advancement of casing into the ground, initiating cap grouting at the soil/bedrock interface, and then installation of grout columns above the cap grouting zone as the casing was removed from the ground. Grout columns are singular elements which compose typical compaction grouting techniques, except in this case a formal grid pattern for the entire building footprint is not established.

The rationale behind this technique is that preventing future sinkhole development is highly improbable, and therefore there are diminishing returns in treating the entire building footprint in floor slab areas and also treating the pinnacle areas in the bedrock. Therefore a plan was devised to treat the soil specifically within the zone of influence of the spread footings as shown in Figure 4.
The intent of the program was not to prevent the development of a sinkhole but to improve the foundation support to better survive a soil dropout and minimize disruption to the military operations if a sinkhole were to occur during the design life of the facility. This was achieved by targeting each spread footing with 3 exploratory grout holes as shown in Figure 5. The intent of each grout injection was 1) to identify the top of rock elevation, 2) determine if a karst feature existed, 3) cap the bedrock in the area and treat the defect in the rock, and 4) provide some localized improvement of soft soils through the use of low mobility grout columns under each footing. This methodology allowed for the individual assessment and comparison of the subsurface conditions at each footing location. Direct comparisons could be made comparing the depth to bedrock and considerations given to the specific subsurface characteristics of each footing to determine whether tertiary holes or significant revisions to the grouting plan would be required. 


\section{Low Mobility Grouting Methodology}

The methodology consisted of advancing casing to the top of bedrock, cap grouting through a port in the casing at the top of bedrock, and finally installation of low mobility grout columns as the casing was withdrawn. Cap grouting was be utilized to reduce infiltration and piping of groundwater and soil material into openings in the bedrock, and provides a barrier that prevents soil loss into bedrock voids. The grout material was thick enough to bridge and choke off small defects in the bedrock surface and withstand soil and hydrostatic pressures, typically 0.3 to 0.61 meters ( 1 to 2 feet) thick. Additionally since cap grouting was only conducted in the structural areas, impacts to the existing groundwater flow regime were minimized.

After cap grouting was completed, low mobility grout columns were used to improve the upper soils by inducing lateral pressures between grout holes at each footing location. The low pressures of the grout injection displaced the native soil which densified the soil overlying bedrock. Typically more compaction effects occur at deeper depths than near the surface of the overburden. This was accomplished by removing the grout pipe in 0.61 meter ( 2 foot) stages and injection of a low mobility grout pumped at a low pressure to form grout columns above the cap grouting zone. Through monitoring the variations in volume and pressure at a constant flow rate, potential karst features or softer, weaker zones of soil can be identified. The casing was removed as the grouting continued such that a continuous series of grout bulbs was created from the bedrock to within 3.05 meters (10 feet) of the ground surface. Grout columns were terminated at this depth below the bottom of the column footings to provide a soil zone below the footing to allow for some natural settlement under the column footings and to reduce differential settlement between the floors, walls, and columns. Other benefits of this technique included strengthening soft soils associated with karst features, reduction of the anticipated total settlement associated with the structure, and increasing the bearing capacity of the soil.

The grout consisted of a stable, sanded grout with a slump between 5.08 to 12.7 centimeters ( 2 to 5 inches). The grout mix did not bleed and had a consistency of mortar. Tight control on the water/cement ratio was maintained through grouting operations. The grout strengths achieved were approximately 5,171 to $8618.4 \mathrm{kPa}$ (750 to $1,250 \mathrm{psi}$ ) to be strong enough to bridge across small voids at the top of the rock. Many grout mix designs are proprietary and will vary based on the grouting equipment, grout pump, soil characteristics, and admixtures.

\section{Low Mobility Grouting Refusal Criteria}

Grout Injection continued within each zone beneath the injection pipe until one or more of the following occurred:

(1) Grout flow ceased at a header pressure reading of $2,757.9 \mathrm{kPa}(400 \mathrm{psi})$

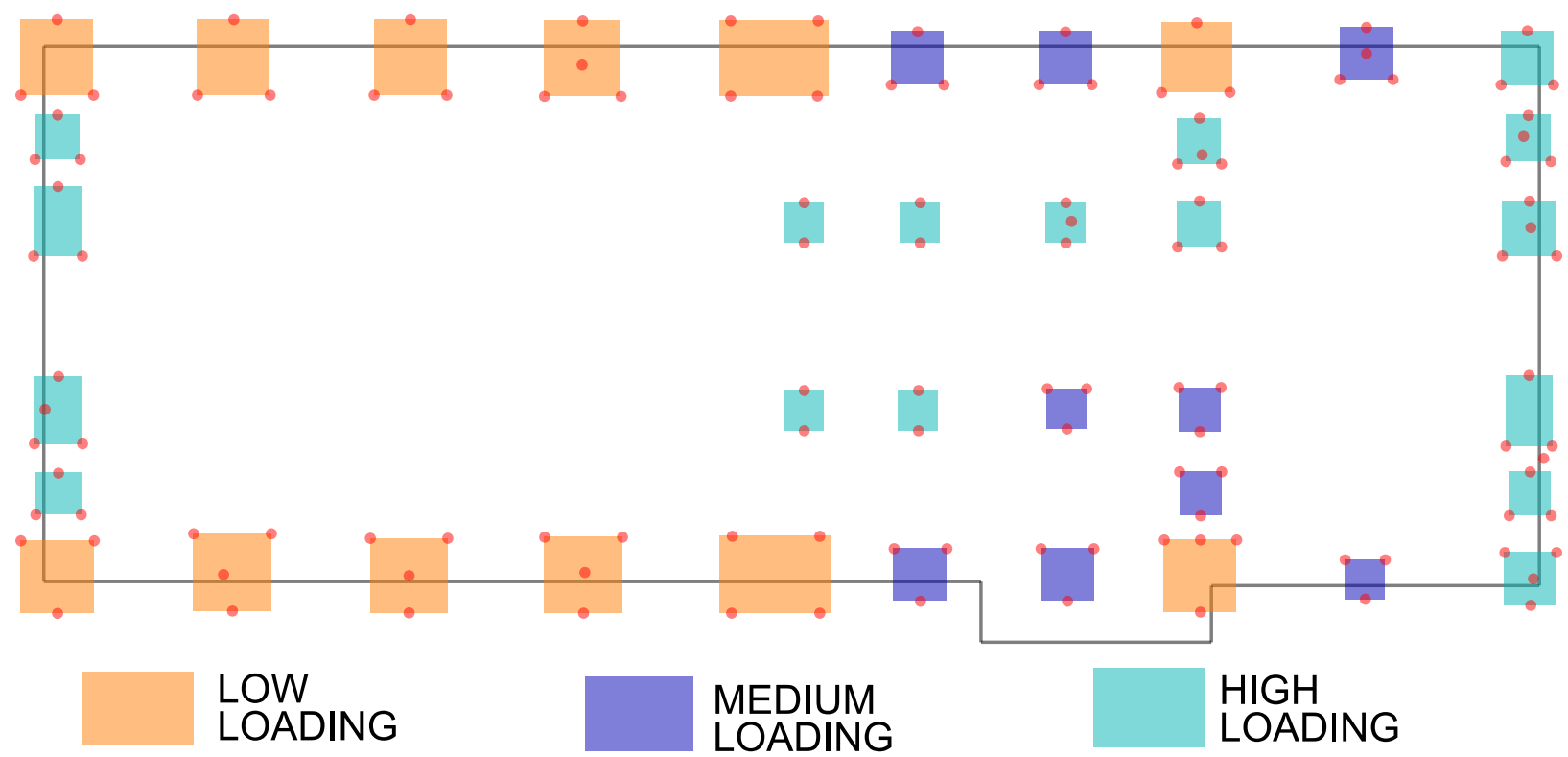

Figure 4. TEMF Foundation Plan with Spread Footings and Grout Injection Locations. 


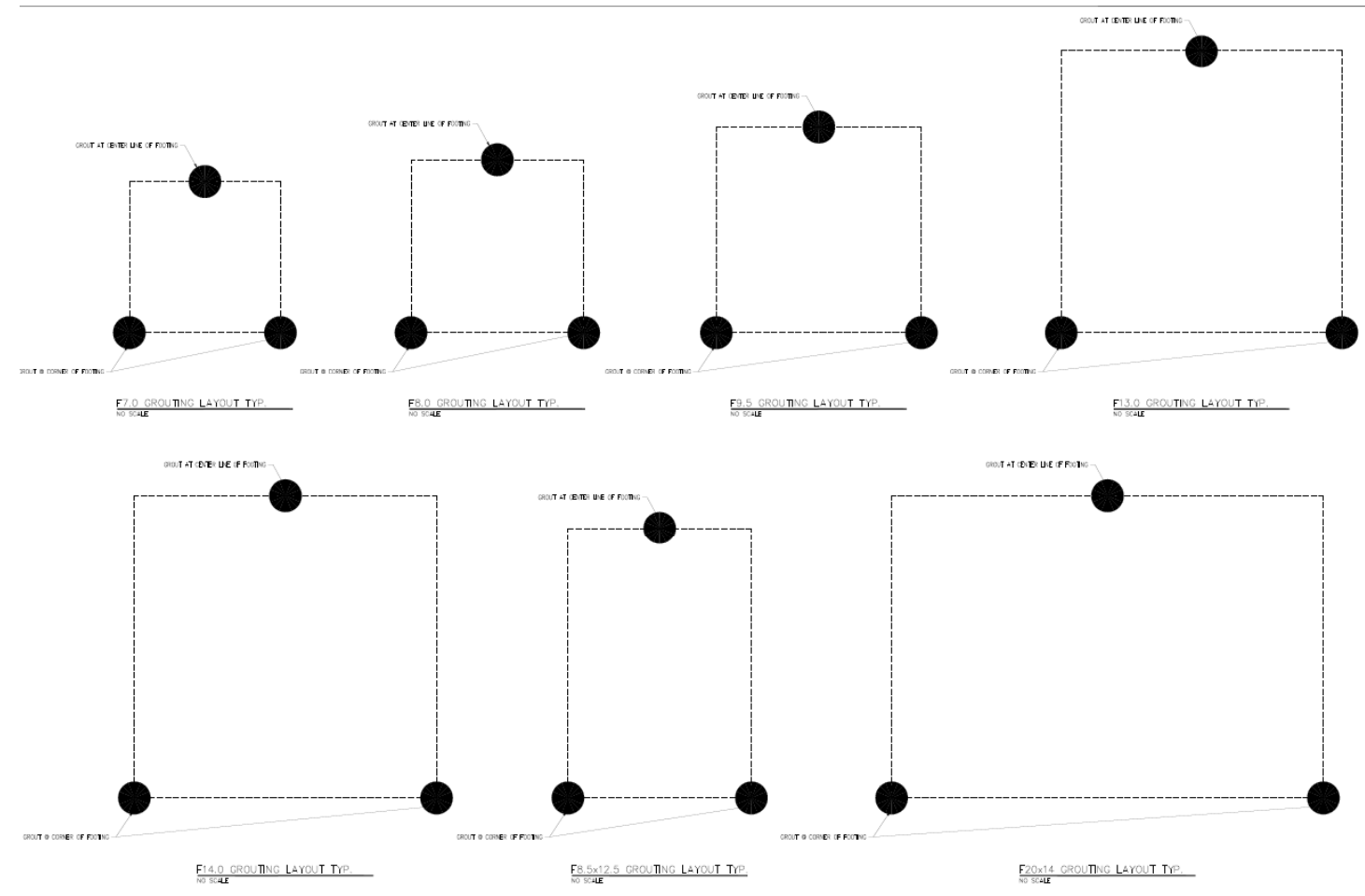

Figure 5. Planned Method of Treating the Subsurface Conditions Under the Structural Elements of the Facility.

(2) A maximum volume of 25 cubic feet of grout was injected immediately above the bedrock surface as part of cap grouting.

(3) Grouting a maximum volume of 10 cubic feet of grout/foot was injected as part of the column grouting to within 3.048 meters ( 10 feet) below the ground surface. The final 3.05 meters (10 feet) of grout was placed by gravity.

(4) Movement of the ground surface if detected evident by ground heave greater than $1.905 \mathrm{~cm}(3 / 4$ inch), or movements of sewer/utility lines of 0.635 $\mathrm{cm}(1 / 4$ inch) were observed.

(5) Grout loss occurring at the ground surface.

(6) Grout intrusion into an underground piping system or grout communication between holes, if detected.

\section{Low Mobility Grouting Pre-Construction Plan- ning}

Due to the proprietary nature of grouting work, specifications should be performance based with sufficient details provided to clearly define the objective and termination criteria required at the site. For this project typical industry standards were used for grouting related to flow rate, volume and pressure termination criteria. The specifica- tion also required the designers to be an integral participant in the decision making process during the grouting program. The project specifications required the submittal of a detailed work plan and a grouting plan by the contractor within 30 days of initiating work. This allowed for a thorough evaluation of the contractor's experience, proposed equipment and methods, and understanding of the project objective. Additionally a pre-construction meeting was required between all stakeholders at which time details of the proposed work plan, specifications, and local geology were discussed in depth. Several key points were refined during these discussions and contingency plans were developed. The need for coordination and discussion prior to mobilization on projects such as this is critical to the overall success and efficiency of the grouting program.

\section{Low Mobility Grouting Summary}

For each grout injection location, a table was produced as shown in Figure 6, which tracked the time, volume, pressure, and refusal criteria. Real time plots of volume and pressure were maintained by the Contractor but were not required for submission in this contract. 
During and after completion of the planned grouting program, the holes were evaluated to assess if tertiary holes were required. Footing locations requiring tertiary holes were selected based on the following criteria:

1. Did the lower portion of the injection take the maximum allowed volume per stage.

2. The pressure sustained while grouting in these zones was less than $1,034.2 \mathrm{kPa}$ (150 psi).

3. The elevations where bedrock was encountered in the grout holes.

The grout injections were evaluated based on the pressures, volumes, and the top of rock elevations to prioritize high risk footings. The bedrock elevations were plotted into a contour map shown in Figure 7. Areas determined to be at most risk for future sinkhole development were identified and targeted with tertiary holes. It is noted that the variation of the apparent top of bedrock elevations at the project site varied substantially more than originally believed by the original geotechnical and geophysical investigations.

The advancement of 15 tertiary holes was recommended for this project. After the tertiary holes were advanced and grouted a noted reduction of volume per stage was documented at increased sustained pressures; signs that soil improvement in these structural areas occurred. This was further verified through selected SPT sampling in areas between the grout holes. The average SPT blow counts at a depth of 7.62 meters (25 feet) prior to the grouting program was 7 , and SPT blow counts after completion of the grouting program was 38. Based on this data, the grouting program was determined to be a success. The final grout program consisted of $359.3 \mathrm{cu}-$ bic meters (470 cubic yards) of grout with 297.4 cubic meters (389 cubic yards) required for grout columns and 61.93 cubic meters (81 cubic yards) required for cap grouting. This required approximately 853.4 meters (2,800 lf) of drilling and casing installation. Each hole was completed for about $\$ 2,500$ with an average depth of 7.01 meters (23 feet) and an average grout take of 4 cubic yards per hole. The final cost including tertiary holes was approximately $\$ 300,000$.

\section{Lessons Learned}

From a geotechnical engineering and foundation design perspective, if posed with a similar design challenge such as this in the future the approach would likely change both during the investigation phase and in the grouting phase. In karst prone areas within the Louisville District COE boundaries the transition away from Electrical Resistivity Imaging and Seismic Refraction in favor of Cone Penetrometer Testing (CPT) has been effective and resulted in cost savings on similar projects when used in conjunction with conventional hollow stem auger and rock coring methods. CPT can be useful for determining refusal depths, characterizing subsurface conditions near the soil/bedrock interface, and for the assessment of potential risk posed by karst. On subsequent projects where karst was a concern using this methodology has actually led to the elimination of some anticipated grouting programs through the additional subsurface information provided. Additionally if shear wave velocities are determined through CPT methods some projects have actually been able to justify improvements to the seismic site classification resulting in significant cost savings.

A typical geotechnical investigation utilizing this approach would consist of 2 building borings extending to the top of bedrock, 2 to 4 additional borings extending

\begin{tabular}{|c|c|c|c|c|c|c|c|c|}
\hline \multicolumn{2}{|c|}{ DEPTH (FT) } & \multicolumn{2}{|c|}{ TIME } & \multirow{2}{*}{$\begin{array}{c}\text { MAX GAUGE } \\
\text { PRESSURE (PSI) }\end{array}$} & \multirow{2}{*}{$\begin{array}{c}\text { MAX HEADER } \\
\text { PRESSURE (PSI) }\end{array}$} & \multicolumn{2}{|c|}{ GROUT QUANTITY } & \multirow[t]{2}{*}{ COMMENTS } \\
\hline TOP & BOTTOM & START & STOP & & & STROKES & $\mathrm{CF}$ & \\
\hline 33 & 34 & 4:13:02 PM & 4:13:10 PM & 200 & 50 & 40 & 25.2 & Max Qty \\
\hline 31 & 33 & 4:13:10 PM & $4: 14: 42$ PM & 200 & 50 & 48 & 30.24 & Max Qty \\
\hline 29 & 31 & 4:14:42 PM & $4: 16: 47$ PM & 200 & 50 & 32 & 20.16 & Max Qty \\
\hline 27 & 29 & 4:16:47 PM & 4:18:19 PM & 200 & 50 & 32 & 20.16 & Max Qty \\
\hline 25 & 27 & 4:18:19 PM & 4:20:19 PM & 200 & 50 & 32 & 20.16 & Max Qty \\
\hline 23 & 25 & 4:20:19 PM & 4:22:32 PM & 200 & 50 & 32 & 20.16 & Max Qty \\
\hline 21 & 23 & 4:22:32 PM & 4:24:13 PM & 200 & 50 & 32 & 20.16 & Max Qty \\
\hline 19 & 21 & $4: 24: 14$ PM & $5: 06: 21 \mathrm{PM}$ & 200 & 50 & 32 & 20.16 & Max Qty \\
\hline 17 & 19 & 5:06:21 PM & 5:09:20 PM & 250 & 50 & 32 & 20.16 & Max Qty \\
\hline 15 & 17 & 5:09:20 PM & $5: 10: 22$ PM & 400 & 50 & 7 & 4.41 & Max Psi \\
\hline 13 & 15 & $5: 10: 22$ PM & 5:11:00 PM & 310 & 50 & 1 & 0.63 & Max Psi \\
\hline 11 & 13 & 5:11:00 PM & 5:11:29 PM & 350 & 50 & 1 & 0.63 & Max Psi \\
\hline 9 & 11 & 5:11:29 PM & 5:12:10 PM & 350 & 50 & 1 & 0.63 & Max Psi \\
\hline 0 & 9 & 5:12:10 PM & 5:13:44 PM & 350 & 50 & 3 & 1.89 & Pump and Pull \\
\hline \multicolumn{6}{|r|}{ TOTALS } & 325 & 204.75 & \\
\hline
\end{tabular}

Figure 6. Typical Grout Log for One Injection Point. 


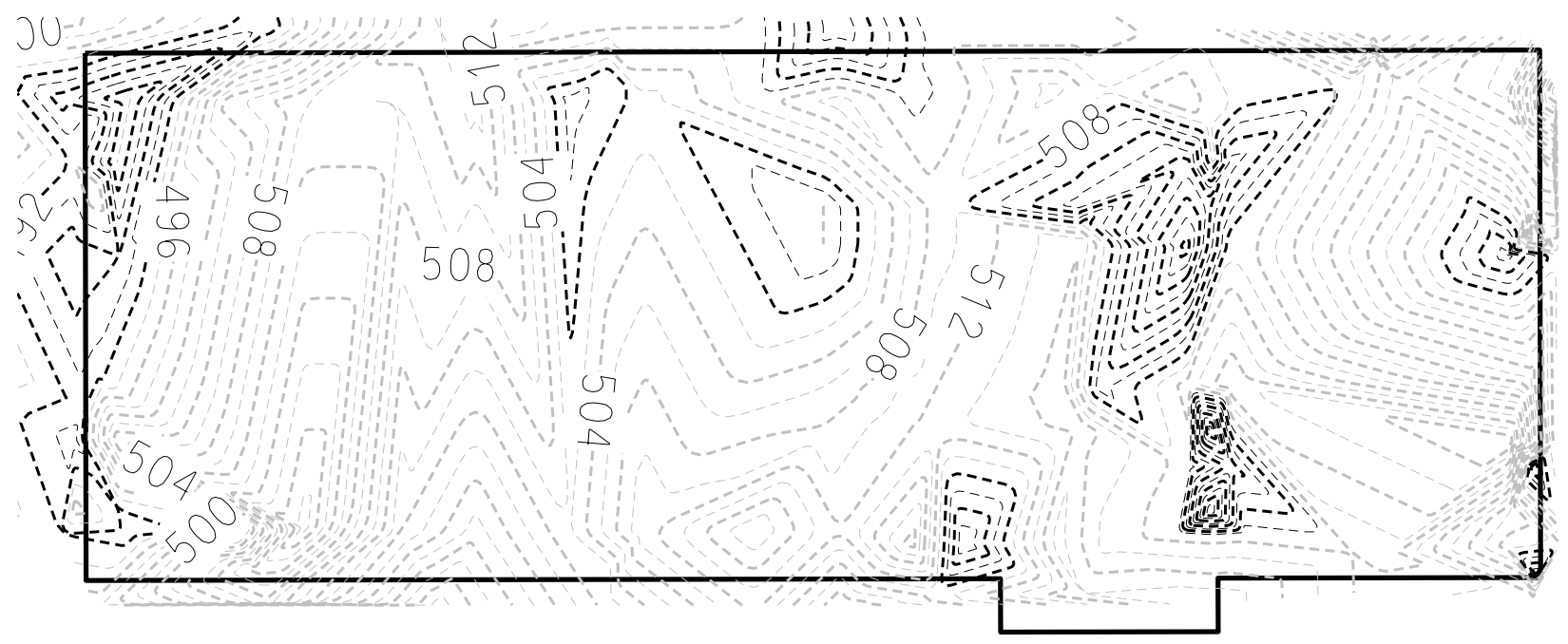

Figure 7. Top of Rock Contour Map Based on Grouting Activities.

to the base of the anticipated zone of influence for the building, combined with an appropriate number of site borings. Then an additional 10 to 40 CPT holes could be advanced to refusal to provide a more tangible top of bedrock surface and estimates for soil properties at depth compared to geophysical methods at a similar cost. Had a grid of CPT holes been advanced at the study site with this methodology the data could have been used to better tailor the grouting program to the most karst prone areas with the weakest soils.

The grouting program itself should be modified to restrict the maximum gage pressure to four times the hydrofracture pressure of the soil. The grouting program improved SPT blow counts by a factor of 5 . This seems to suggest the program was highly effective, but inefficiencies in the grouting program can result from hydrofracture of the soil. Considering the grouting program allowed the industrial standard of 2,757.9 $\mathrm{kPa}$ (400 psi) gauge pressure for grout holes that extended between 6.1 and 13.7 meters (20 and 45 feet) below the ground surface, a pressure 10 to 12 times the hydrofracture pressure of the soil at those depths was routinely introduced at the study site. A reduction of the allowable grouting pressures would have resulted in a lower grout volume required to achieve the desired subsurface improvement.

Several methods of determining the hydrofracture pressure exist. The simplest form of the equation was presented by Mori and Tamura in 1987 where the hydrofracture pressure is represented by the equation:

$$
P_{f}=\sigma_{3}+q_{u}
$$

Where $\mathrm{P}_{\mathrm{f}}=$ Maximum allowable pressure to initiate hydraulic fracture, $\sigma_{3}=$ Horizontal Stress (Minor Principle Stress), and $\mathrm{q}_{\mathrm{u}}=$ Unconfined Compressive Strength. Applying this equation to the case study site at a depth of 7.62 meters ( 25 feet) below the ground surface you obtain a hydrofracture pressure which is determined as follows:

\begin{tabular}{|r|l|}
\hline Vertical Stress, $\sigma 1$ & $=25 \mathrm{ft}^{*}(125 \mathrm{pcf})$ \\
& $=3,125 \mathrm{psf}$ \\
& $=149.6 \mathrm{kPa}$ \\
\hline Horizontal Stress & $=(\mu / 1-\mu)\left(\sigma_{1}\right)$ \\
$\left(\sigma_{3}\right)$ & $=(0.4 / 1-0.4)(3,125 \mathrm{psf})$ \\
& $=2,083 \mathrm{psf}$ \\
& $=99.7 \mathrm{kPa}$ \\
\hline
\end{tabular}

Where $\mu=$ Poisson's Ratio $=0.4$ and qu $=143.6 \mathrm{kPa}$ $(3,000 \mathrm{psf})$ as determined by laboratory testing. Therefore $\mathrm{P}_{\mathrm{f}}=99.7 \mathrm{kPa}+143.6 \mathrm{kPa}=243.4 \mathrm{kPa}$ $\left(\mathrm{P}_{\mathrm{f}}=2,083 \mathrm{psf}+3,000 \mathrm{psf}=5,083 \mathrm{psf}=35 \mathrm{psi}\right)$ and hydraulic fracture of the soils can occur at pressures as low as $243.4 \mathrm{kPa}$ (35 psi). An example of hydraulic fracture is shown in Figure 8.

Some hydrofracture of the soils should be anticipated and in a controlled manner can be effective. However considering one objective of a low mobility grouting program is to densify soft/weak soils, using pressures as high as $2,757.9 \mathrm{kPa}$ (400 psi) results in instances where a lot more grout can be pumped into the ground than is actually needed to improve the soils. This is because severe hydrofracture causes erratic grout travel, excessive grout takes with minimal soil improvement, and sometimes unwanted damage. 


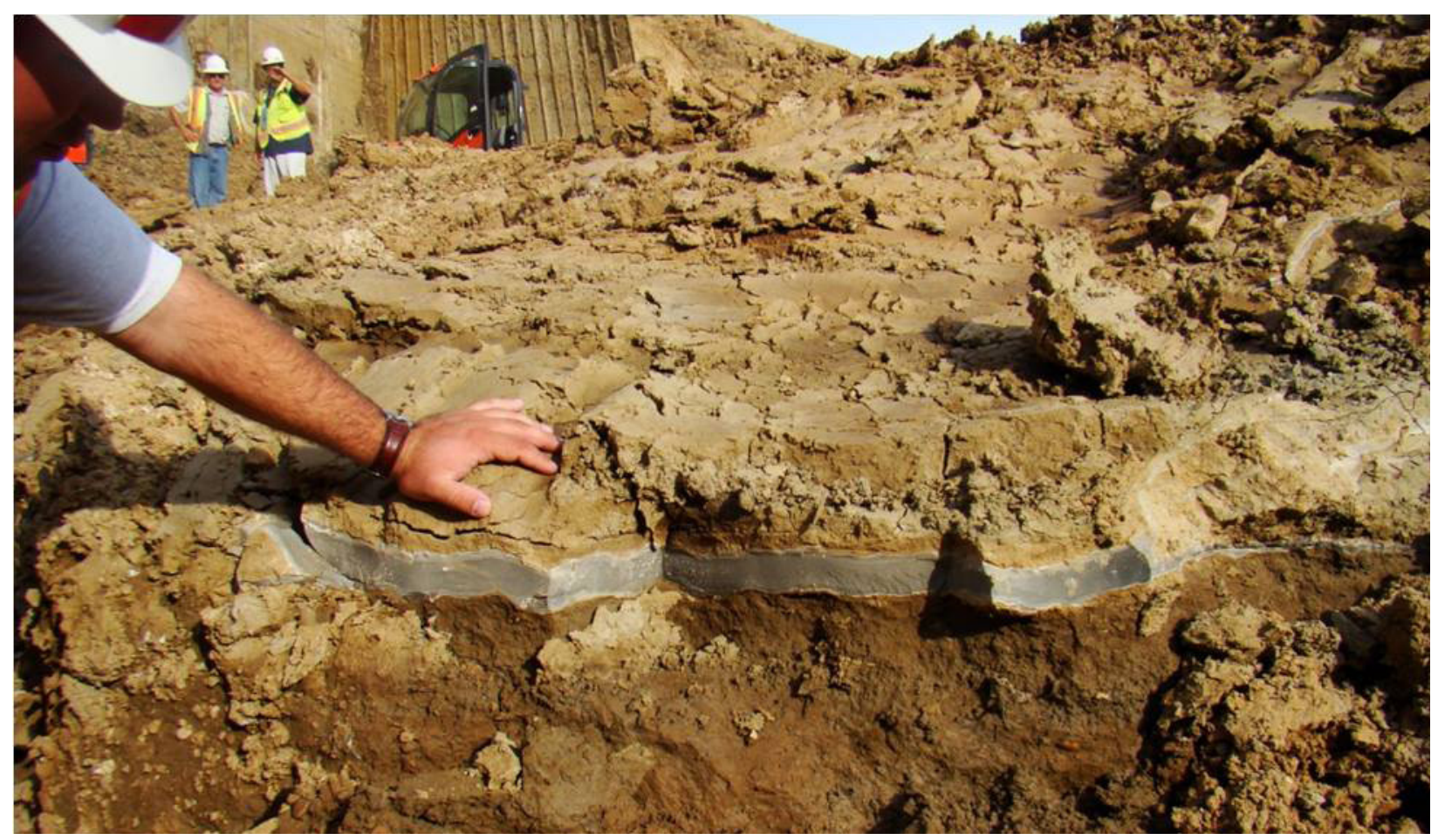

Figure 8. Hydraulic Fracture in Clay Soils at KY Lock and Dam.

Based on this experience, future foundation grouting projects should consider reducing the maximum allowable gage pressure to between 861.8 to $1379 \mathrm{kPa}$ (125 to $200 \mathrm{psi}$ ). This was the pressure threshold where tertiary holes were warranted in this case study. However if every stage was terminated at $1379 \mathrm{kPa}(200 \mathrm{psi})$ considerable savings would have been recognized in the 297.4 cubic meters ( 389 cubic yards) of low mobility column grouting that occurred, possibly as much as $50 \%$ of the total grout quantity. Some hydrofracture of the soils would still occur, but a better balance between the total volume of grout expended from hydrofracture and soil improvement would be achieved using reduced pressures at the same flow rate.

\section{Conclusion}

The grouting methodologies utilized on this project improved soil strength in zones where very low shear strengths were encountered. The methodology allowed for specific assessment and treatment based on the founding conditions at each structural element of the facility. The information gathered during the grouting program allowed for better certainty regarding the top of rock elevations at the site. There are no guarantees that future sinkhole development will not impact this facility, but the extent of potential structural damage to the facility has been minimized. Additionally, a perfor- mance specification using industry standards in grouting is functional, but as practices are advanced and evolve designers should be cognizant that more efficient methods and processes can still be explored and refined to minimize costs and maximize benefits associated with pre-treatment of high-risk soils in critical structural areas, and even to practices applied for sinkhole repair.

\section{Reference}

Mori A, Tamura M. 1987. Hydrofracturing pressure of cohesive soils. Soils and Foundations 27 (1): 1422. 